\title{
Methodology Statement
}

AARP's Salud, Dinero y Amor In The Time of COVID-19 study was conducted by ThinkNow. The survey was administered online among a national sample of $n=1,000$ self-identified Hispanic adults age 35 years and older; and $n=362$ non-Hispanic adults age 35 and older.

The survey was fielded between September 1-13, 2020. A survey invitation was emailed to a random set of respondents from opt-in online panels who were profiled as Hispanic and 35 year of age and older. Respondents completed a short screener to confirm their race/ethnicity, age, zip code and home language use. Quotas were used to ensure an even balance of SpanishDominant, Bilingual and English-Dominant respondents. The screener and main survey were offered in English and Spanish.

Where appropriate, response options in close-end questions and items in rating/grid questions were randomized to prevent order bias. All data was cleaned on the back-end by removing respondents who were identified as "speedsters" (completed the survey in a shorter time than expected for the number of questions) or "straight-liners" (same response selected in grid questions) and for providing gibberish or non-sensical verbatim responses to open-ended questions.

For the Hispanic sample, data was weighted by age group, registered voter and gender to more closely align with population benchmarks for Hispanics 35 years of age and older based on the November 2018 Current Population Survey. For the non-Hispanic segment, the data was weighted by age group and gender to U.S. Census targets for non-Hispanics 35 and over. We did not weight the segments further or by additional variables in order to maintain the design effect/effective sample size.

\begin{tabular}{|l|c|c|c|}
\hline \multicolumn{1}{|c|}{ Weighting Variables } & $\begin{array}{c}\text { Unweighted } \\
\text { Sample }\end{array}$ & $\begin{array}{c}\text { U.S. Census } \\
\text { Benchmark }\end{array}$ & $\begin{array}{c}\text { Weighted } \\
\text { Sample }\end{array}$ \\
\hline Hispanics 35+ & & & \\
\hline Aged 35 to 49 & $64 \%$ & $49 \%$ & $50 \%$ \\
\hline Aged 50 and over & $36 \%$ & $51 \%$ & $40 \%$ \\
\hline & & & $55 \%$ \\
\hline Registered Voter & $70 \%$ & $40 \%$ & $45 \%$ \\
\hline Non-Registered & $30 \%$ & $60 \%$ & \\
\hline & & & $50 \%$ \\
\hline Males & $48 \%$ & $50 \%$ & $50 \%$ \\
\hline Females & $52 \%$ & $50 \%$ & \\
\hline & & & $40 \%$ \\
\hline Non-Hispanics 35+ & & & $60 \%$ \\
\hline Aged 35 to 49 & $54 \%$ & $32 \%$ & \\
\hline Aged 50 and over & $46 \%$ & $68 \%$ & $50 \%$ \\
\hline & & & $50 \%$ \\
\hline Males & $50 \%$ & $50 \%$ & \\
\hline Females & $50 \%$ & $50 \%$ & \\
\hline
\end{tabular}

